Research Article

\title{
Solutions of a Class of Deviated-Advanced Nonlocal Problems for the Differential Inclusion $x^{1}(t) \in F(t, x(t))$
}

\author{
A. M. A. El-Sayed, ${ }^{1}$ E. M. Hamdallah, ${ }^{1}$ and Kh. W. Elkadeky ${ }^{2}$ \\ ${ }^{1}$ Faculty of Science, Alexandria University, Alexandria, Egypt \\ ${ }^{2}$ Faculty of Science, Garyounis University, Benghazi, Libya
}

Correspondence should be addressed to Kh. W. Elkadeky, k_welkadeky@yahoo.com

Received 19 January 2011; Accepted 27 April 2011

Academic Editor: Stephen Clark

Copyright (C) 2011 A. M. A. El-Sayed et al. This is an open access article distributed under the Creative Commons Attribution License, which permits unrestricted use, distribution, and reproduction in any medium, provided the original work is properly cited.

We study the existence of solutions for deviated-advanced nonlocal and integral condition problems for the differential inclusion $x^{1}(t) \in F(t, x(t))$.

\section{Introduction}

Problems with nonlocal conditions have been extensively studied by several authors in the last two decades. The reader is referred to [1-12] and references therein. Consider the deviated-advanced nonlocal problem

$$
\begin{gathered}
\frac{d x(t)}{d t} \in F(t, x(t)), \quad \text { a.e. } t \in(0,1), \\
\sum_{k=1}^{m} a_{k} x\left(\phi\left(\tau_{k}\right)\right)=\alpha \sum_{j=1}^{n} b_{j} x\left(\psi\left(\eta_{j}\right)\right), \quad a_{k}, b_{j}>0,
\end{gathered}
$$

where $\tau_{k}, \eta_{j} \in(0,1), \alpha>0$ is a parameter, and $\psi$ and $\phi$ are, respectively, deviated and advanced given functions.

Our aim here is to study the existence of at least one absolutely continuous solution $x \in \mathrm{AC}[0,1]$ for the problem (1.1)-(1.2) when the set-valued function $F: R \rightarrow P(R)$ is $L^{1}$-Carathéodory. 
As an application, we deduce the existence of a solution for the nonlocal problem of the differential inclusion (1.1) with the deviated-advanced integral condition

$$
\int_{0}^{1} x(\phi(s)) d s=\alpha \int_{0}^{1} x(\psi(s)) d s
$$

It must be noticed that the following nonlocal and integral conditions are special cases of our nonlocal and integral conditions

$$
\begin{gathered}
x(\phi(\tau))=\alpha x(\psi(\eta)), \quad \tau, \eta \in(0,1), \\
\sum_{k=1}^{m} a_{k} x\left(\phi\left(\tau_{k}\right)\right)=\alpha x(\psi(\eta)), \quad \tau_{k}, \eta \in(0,1), \\
\sum_{k=1}^{m} a_{k} x\left(\phi\left(\tau_{k}\right)\right)=0, \quad \tau_{k} \in(0,1), \\
\int_{0}^{1} x(\phi(s)) d s=\alpha x(\psi(\eta)), \quad \eta \in(0,1), \\
\alpha \int_{0}^{1} x(\psi(s)) d s=x(\phi(\tau)), \quad \tau \in(0,1), \\
\int_{0}^{1} x(\phi(s)) d s=0 \\
\int_{0}^{1} x(\psi(s)) d s=0 .
\end{gathered}
$$

As an example of the deviated function $\phi:(0,1) \rightarrow(0,1)$, we have $\phi(t)=\beta t, \beta \in(0,1)$. As an example of the advanced function $\psi:(0,1) \rightarrow(0,1)$, we have $\psi(t)=t^{\beta}, \beta \in(0,1)$.

\section{Preliminaries}

The following preliminaries are needed.

Definition 2.1. A set-valued function $F:[0,1] \times R \rightarrow P(R)$ is called $L^{1}$-Carathéodory if

(a) $t \rightarrow F(t, x)$ is measurable for each $x \in R$,

(b) $x \rightarrow F(t, x)$ is upper semicontinuous for almost all $t \in[0,1]$,

(c) there exists $m \in L^{1}([0,1], D), D \subset R$ such that

$$
|F(t, x)|=\sup \{|v|: v \in F(t, x)\} \leq m(t), \quad \text { for almost all } t \in[0,1]
$$

Definition 2.2. A single-valued function $f:[0,1] \times R \rightarrow R$ is called $L^{1}$-Carathéodory if

(i) $t \rightarrow f(t, x)$ is measurable for each $x \in R$, 
(ii) $x \rightarrow f(t, x)$ is continuous for almost all $t \in[0,1]$,

(iii) there exists $m \in L^{1}([0,1], D), D \subset R$ such that $|f| \leq m$.

Definition 2.3. The set

$$
S_{F(\cdot, x(t))}^{1}=\{f \in([0,1], R): f(t, x) \in F(t, x(t)) \text { for a.e. } t \in[0,1]\}
$$

is called the set of selections of the set-valued function $F$.

Theorem 2.4. For any $L^{1}$-Carathéodory set-valued function $F$, the set $S_{F(\cdot, x(t))}^{1}$ is nonempty [1, 13].

Theorem 2.5 (Carathéodory, [14]). Let $f:[0,1] \times R \rightarrow R$ be $L^{1}$-Carathéodory. Then the problem

$$
\frac{d x(t)}{d t}=f(t, x(t)), \quad \text { for a.e. } t>0, x(0)=x_{0},
$$

has at least one solution $x \in \mathrm{AC}[0, T]$.

\section{Existence of Solution}

Consider the following assumptions.

(i) $F:[0,1] \times R \rightarrow P\left(R^{+}\right)$is $L^{1}$-Carathéodory.

(ii)

$$
\alpha \sum_{j=1}^{n} b_{j} \neq \sum_{k=1}^{m} a_{k}
$$

(iii) $\phi:(0,1) \rightarrow(0,1), \phi(t) \leq t$ is a deviated continuous function.

(iv) $\psi:(0,1) \rightarrow(0,1), \psi(t) \geq t$ is an advanced continuous function.

Now we have the following lemma.

Lemma 3.1. Let assumptions (i)-(ii) be satisfied. The solution of the nonlocal problem (1.1)-(1.2) can be expressed by the integral equation

$$
x(t)=A\left(\sum_{k=1}^{m} a_{k} \int_{0}^{\phi\left(\tau_{k}\right)} f(s, x(s)) d s-\alpha \sum_{j=1}^{n} b_{j} \int_{0}^{\psi\left(\eta_{j}\right)} f(s, x(s)) d s\right)+\int_{0}^{t} f(s, x(s)) d s,
$$

where $f(t, x) \in F(t, x)$, for all $x \in R$, and $A=\left(\alpha \sum_{j=1}^{n} b_{j}-\sum_{k=1}^{m} a_{k}\right)^{-1}$. 
Proof. From the assumption that the set-valued function $F:[0,1] \times R \rightarrow P\left(R^{+}\right)$is $L^{1}$ Carathéodory, then (Theorem 2.4) there exists a single-valued selection $f:[0,1] \times R \rightarrow R^{+}$ such that

$$
\frac{d}{d t} x(t)=f(t, x) \in F(t, x), \quad \forall x \in R
$$

This selection $f(t, x)$ is $L^{1}$-Carathéodory.

Integrating (3.3), we get

$$
x(t)=x(0)+\int_{0}^{t} f(s, x(s)) d s
$$

Let $t=\phi\left(\tau_{k}\right)$. Then

$$
\sum_{k=1}^{m} a_{k} x\left(\phi\left(\tau_{k}\right)\right)=\sum_{k=1}^{m} a_{k} x(0)+\sum_{k=1}^{m} a_{k} \int_{0}^{\phi\left(\tau_{k}\right)} f(s, x(s)) d s
$$

Let $t=\psi\left(\eta_{j}\right)$. Then

$$
\alpha \sum_{j=1}^{n} b_{j} x\left(\psi\left(\eta_{j}\right)\right)=\alpha \sum_{j=1}^{n} b_{j} x(0)+\alpha \sum_{j=1}^{n} b_{j} \int_{0}^{\psi\left(\eta_{j}\right)} f(s, x(s)) d s
$$

From (3.5) and (3.6), we obtain

$$
x(0)=A\left(\sum_{k=1}^{m} a_{k} \int_{0}^{\phi\left(\tau_{k}\right)} f(s, x(s)) d s-\alpha \sum_{j=1}^{n} b_{j} \int_{0}^{\psi\left(\eta_{j}\right)} f(s, x(s)) d s\right),
$$

where $A=\left(\alpha \sum_{j=1}^{n} b_{j}-\sum_{k=1}^{m} a_{k}\right)^{-1}, \alpha \sum_{j=1}^{n} b_{j} \neq \sum_{k=1}^{m} a_{k}$.

Substituting (3.7) into (3.4), we obtain

$$
x(t)=A\left(\sum_{k=1}^{m} a_{k} \int_{0}^{\phi\left(\tau_{k}\right)} f(s, x(s)) d s-\alpha \sum_{j=1}^{n} b_{j} \int_{0}^{\psi\left(\eta_{j}\right)} f(s, x(s)) d s\right)+\int_{0}^{t} f(s, x(s)) d s
$$

This proves that the solution of the nonlocal problem (1.1)-(1.2) can be expressed by the integral equation (3.2).

For the existence of the solution, we have the following theorem.

Theorem 3.2. Assume that (i)-(iv) are satisfied. Then the integral equation (3.2) has at least one continuous solution $x \in C[0,1]$. 
Proof. Define a subset $Q_{r} \subset C[0,1]$ by

$$
Q_{r}=\left\{x \in C[0,1]:|x(t)| \leq r, r=A M\left(1+\sum_{k=1}^{m} a_{k}+\alpha \sum_{j=1}^{n} b_{j}\right)\right\} \text {. }
$$

Clearly, the set $Q_{r}$ is nonempty, closed, and convex.

Let $H$ be an operator defined by

$$
(H x)(t)=A\left(\sum_{k=1}^{m} a_{k} \int_{0}^{\phi\left(\tau_{k}\right)} f(s, x(s)) d s-\alpha \sum_{j=1}^{n} b_{j} \int_{0}^{\psi\left(\eta_{j}\right)} f(s, x(s)) d s\right)+\int_{0}^{t} f(s, x(s)) d s .
$$

Let $x \in Q_{r}$. Let $\left\{x_{n}(t)\right\}$ be a sequence in $Q_{r}$ converging to $x(t), x_{n}(t) \rightarrow x(t)$, for all $t \in I$. Then

$$
\begin{aligned}
\lim _{n \rightarrow \infty}\left(H x_{n}\right)(t)= & A\left(\sum_{k=1}^{m} a_{k} \lim _{n \rightarrow \infty} \int_{0}^{\phi\left(\tau_{k}\right)} f\left(s, x_{n}(s)\right) d s-\alpha \sum_{j=1}^{n} b_{j} \lim _{n \rightarrow \infty} \int_{0}^{\psi\left(\eta_{j}\right)} f\left(s, x_{n}(s)\right) d s\right) \\
& +\lim _{n \rightarrow \infty} \int_{0}^{t} f\left(s, x_{n}(s)\right) d s,
\end{aligned}
$$

By assumptions (i)-(ii) and the Lebesgue dominated convergence theorem, we deduce that

$$
\lim _{n \rightarrow \infty}\left(H x_{n}\right)(t)=(H x)(t) .
$$

Then $H$ is continuous.

Now, letting $x \in Q_{r}$, (then $\phi(t) \leq t$ and $\left.\psi(t) \geq t\right)$, we obtain

$$
\begin{aligned}
(H x)(t) \leq & A\left(\sum_{k=1}^{m} a_{k} \int_{0}^{\tau_{k}} f(s, x(s)) d s-\alpha \sum_{j=1}^{n} b_{j} \int_{0}^{\eta_{j}} f(s, x(s)) d s\right) \\
& +\int_{0}^{t} f(s, x(s)) d s, \\
|(H x)(t)| \leq & A\left(\sum_{k=1}^{m} a_{k} \int_{0}^{\tau_{k}}|f(s, x(s))| d s+\alpha \sum_{j=1}^{n} b_{j} \int_{0}^{\eta_{j}}|f(s, x(s))| d s\right) \\
& +\int_{0}^{t}|f(s, x(s))| d s \\
\leq & A\left(\sum_{k=1}^{m} a_{k} \int_{0}^{\tau_{k}} m(s) d s+\alpha \sum_{j=1}^{n} b_{j} \int_{0}^{\eta_{j}} m(s) d s\right)+\int_{0}^{t} m(s) d s
\end{aligned}
$$




$$
\begin{aligned}
& \leq A\left(\sum_{k=1}^{m} a_{k} M+\alpha \sum_{j=1}^{n} b_{j} M\right)+M \\
& \leq A M\left(1+\sum_{k=1}^{m} a_{k}+\alpha \sum_{j=1}^{n} b_{j}\right) \leq r .
\end{aligned}
$$

Then $\{H x(t)\}$ is uniformly bounded in $Q_{r}$.

Also for $t_{1}, t_{2} \in(0,1), t_{1}<t_{2}$ such that $\left|t_{2}-t_{1}\right|<\delta$, we have

$$
\begin{gathered}
(H x)\left(t_{2}\right)-(H x)\left(t_{1}\right)=\int_{0}^{t_{2}} f(s, x(s)) d s-\int_{0}^{t_{1}} f(s, x(s)) d s, \\
\left|(H x)\left(t_{2}\right)-(H x)\left(t_{1}\right)\right| \leq \int_{t_{1}}^{t_{2}}|f(s, x(s))| d s \\
\leq \int_{t_{1}}^{t_{2}} m(s) d s, \\
\left|(H x)\left(t_{2}\right)-(H x)\left(t_{1}\right)\right| \leq \varepsilon .
\end{gathered}
$$

Hence the class of functions $\{H x(t)\}$ is equicontinuous. By Arzela-Ascoli's theorem, $\{H x(t)\}$ is relatively compact. Since all conditions of Schauder's theorem hold, then $H$ has a fixed point in $Q_{r}$. Now,

Therefore the integral equation (3.2) has at least one continuous solution $x \in C(0,1)$.

$$
\begin{aligned}
\lim _{t \rightarrow 0} x(t)= & A \lim _{t \rightarrow 0}\left(\sum_{k=1}^{m} a_{k} \int_{0}^{\phi\left(\tau_{k}\right)} f(s, x(s)) d s-\alpha \sum_{j=1}^{n} b_{j} \int_{0}^{\psi\left(\eta_{j}\right)} f(s, x(s)) d s\right) \\
& +\lim _{t \rightarrow 0} \int_{0}^{t} f(s, x(s)) d s \\
= & A\left(\sum_{k=1}^{m} a_{k} \int_{0}^{\phi\left(\tau_{k}\right)} f(s, x(s)) d s-\alpha \sum_{j=1}^{n} b_{j} \int_{0}^{\psi\left(\eta_{j}\right)} f(s, x(s)) d s\right)=x(0) .
\end{aligned}
$$

Also

$$
\begin{aligned}
x(1)= & \lim _{t \rightarrow 1} x(t)=A\left(\sum_{k=1}^{m} a_{k} \int_{0}^{\phi\left(\tau_{k}\right)} f(s, x(s)) d s-\alpha \sum_{j=1}^{n} b_{j} \int_{0}^{\phi\left(\eta_{j}\right)} f(s, x(s)) d s\right) \\
& +\int_{0}^{1} f(s, x(s)) d s .
\end{aligned}
$$

Then the integral equation (3.2) has at least one continuous solution $x \in C[0,1]$. 
The following theorem proves the existence of at least one solution for the nonlocal problem(1.1)-(1.2).

Theorem 3.3. Let (i)-(iv) be satisfied. Then the nonlocal problem (1.1)-(1.2) has at least one solution $x \in \mathrm{AC}[0,1]$.

Proof. From Theorem 3.2 and the integral equation (3.2), we deduce that there exists at least one solution, $x \in \mathrm{AC}[0,1]$, of the integral equation (3.2).

To complete the proof, we prove that the integral equation (3.2) satisfies nonlocal problem (1.1)-(1.2).

Differentiating (3.2), we get

$$
\frac{d x}{d t}=f(t, x(t)) \in F(t, x(t)), \quad \text { a.e. } t \in(0,1)
$$

Letting $t=\phi\left(\tau_{k}\right)$ in (3.2), we obtain

$$
\sum_{k=1}^{m} a_{k} x\left(\phi\left(\tau_{k}\right)\right)=\sum_{k=1}^{m} a_{k}\left(A \sum_{k=1}^{m} a_{k}+1\right) \int_{0}^{\phi\left(\tau_{k}\right)} f(s, x(s)) d s-\alpha A \sum_{k=1}^{m} a_{k} \sum_{j=1}^{n} b_{j} \int_{0}^{\psi\left(\eta_{j}\right)} f(s, x(s)) d s .
$$

Also, letting $t=\psi\left(\eta_{j}\right)$ in (3.2), we obtain

$$
\begin{aligned}
\alpha \sum_{j=1}^{n} b_{j} x\left(\psi\left(\eta_{j}\right)\right)= & \alpha A \sum_{j=1}^{n} b_{j} \sum_{k=1}^{m} a_{k} \int_{0}^{\phi\left(\tau_{k}\right)} f(s, x(s)) d s \\
& +\alpha \sum_{j=1}^{n} b_{j}\left(1-\alpha A \sum_{j=1}^{n} b_{j}\right) \int_{0}^{\psi\left(\eta_{j}\right)} f(s, x(s)) d s .
\end{aligned}
$$

And from (3.19) from (3.18), we obtain

$$
\sum_{k=1}^{m} a_{k} x\left(\phi\left(\tau_{k}\right)\right)=\alpha \sum_{j=1}^{n} b_{j} x\left(\psi\left(\eta_{j}\right)\right)
$$

This complete the proof of the equivalence between the nonlocal problem (1.1)-(1.2) and the integral equation (3.2).

This implies that there exists at least one absolutely continuous solution $x \in \mathrm{AC}[0,1]$ of the nonlocal problem (1.1)-(1.2). 


\section{Nonlocal Integral Condition}

Let $x \in[0,1]$ be a solution of the nonlocal problem (1.1)-(1.2). Let $a_{k}=t_{k}-t_{k-1}, \tau_{k} \in$ $\left(t_{k-1}, t_{k}\right) \subset(0,1)$. Also, let $b_{j}=t_{j}-t_{j-1}, \eta_{j} \in\left(t_{j-1}, t_{j}\right) \subset(0,1)$. Then the nonlocal condition (1.2) will be

$$
\sum_{k=1}^{m}\left(t_{k}-t_{k-1}\right) x\left(\phi\left(\tau_{k}\right)\right)=\alpha \sum_{j=1}^{n}\left(t_{j}-t_{j-1}\right) x\left(\psi\left(\eta_{j}\right)\right) .
$$

From the continuity of the solution $x$ of the nonlocal condition (1.2) we obtain

$$
\lim _{m \rightarrow \infty} \sum_{k=1}^{m}\left(t_{k}-t_{k-1}\right) x\left(\phi\left(\tau_{k}\right)\right)=\lim _{n \rightarrow \infty} \alpha \sum_{j=1}^{n}\left(t_{j}-t_{j-1}\right) x\left(\psi\left(\eta_{j}\right)\right)
$$

That is, the nonlocal condition (1.2) is transformed to the integral condition

$$
\int_{0}^{1} x(\phi(s)) d s=\alpha \int_{0}^{1} x(\psi(s)) d s
$$

and the solution of the integral equation (3.2) will be

$$
\begin{aligned}
x(t)= & A^{*}\left(\int_{0}^{1} \int_{0}^{\phi(s)} f(\theta, x(\theta)) d \theta d s-\alpha \int_{0}^{1} \int_{0}^{\psi(s)} f(\theta, x(\theta)) d \theta d s\right) \\
& +\int_{0}^{t} f(s, x(s)) d s, \quad A^{*}=(\alpha-1)^{-1} .
\end{aligned}
$$

Now, we have the following theorem.

Theorem 4.1. Let assumptions (i)-(iv) of Theorem 3.2 be satisfied. Then the nonlocal problem with the integral condition

$$
\begin{aligned}
\frac{d x(t)}{d t}= & f(t, x(t)) \in F(t, x(t)), \quad \text { for a.e. } t \in(0,1), \\
& \int_{0}^{1} x(\phi(s)) d s=\alpha \int_{0}^{1} x(\psi(s)) d s
\end{aligned}
$$

has at least one solution $x \in A C[0,1]$ represented by (4.4).

\section{References}

[1] A. Boucherif, "First-order differential inclusions with nonlocal initial conditions," Applied Mathematics Letters, vol. 15, no. 4, pp. 409-414, 2002.

[2] A. Boucherif, "Nonlocal Cauchy problems for first-order multivalued differential equations," Electronic Journal of Differential Equations, vol. 2002, no. 47, pp. 1-9, 2002. 
[3] A. Boucherif and R. Precup, "On the nonlocal initial value problem for first order differential equations," Fixed Point Theory, vol. 4, no. 2, pp. 205-212, 2003.

[4] A. Boucherif, "Semilinear evolution inclusions with nonlocal conditions," Applied Mathematics Letters, vol. 22, no. 8, pp. 1145-1149, 2009.

[5] M. Benchohra, E. P. Gatsori, and S. K. Ntouyas, "Existence results for semi-linear integrodifferential inclusions with nonlocal conditions," The Rocky Mountain Journal of Mathematics, vol. 34, no. 3, pp. 833-848, 2004.

[6] M. Benchohra, S. Hamani, and S. Ntouyas, "Boundary value problems for differential equations with fractional order and nonlocal conditions," Nonlinear Analysis, Theory, Methods \& Applications, vol. 71, no. 7-8, pp. 2391-2396, 2009.

[7] A. M. A. El-Sayed and S. A. Abd El-Salam, "On the stability of a fractional-order differential equation with nonlocal initial condition," Electronic Journal of Qualitative Theory of Differential Equations, vol. 2009, no. 29, pp. 1-8, 2009.

[8] A. M. A El-Sayed and E. O Bin-Taher, "A nonlocal problem of an arbitrary (fractional) orders differential equation," Alexandria Journal of Mathematics, vol. 1, no. 2, pp. 1-7, 2010.

[9] A. M. A. El-Sayed and Kh. W. Elkadeky, "Caratheodory theorem for a nonlocal problem of the differential equation $x^{\prime}=f\left(t, x^{\prime}\right)$, , Alexandria Journal of Mathematics, vol. 1, no. 2, pp. 8-14, 2010.

[10] E. Gatsori, S. K. Ntouyas, and Y. G. Sficas, "On a nonlocal Cauchy problem for differential inclusions," Abstract and Applied Analysis, vol. 2004, no. 5, pp. 425-434, 2004.

[11] G. M. A. Guerekata, "Cauchy problem for some fractional abstract differential equation with non local conditions," Nonlinear Analysis, Theory, Methods \& Applications, vol. 70, no. 5, pp. 1873-1876, 2009.

[12] R. Ma, "Existence and uniqueness of solutions to first-order three-point boundary value problems," Applied Mathematics Letters, vol. 15, no. 2, pp. 211-216, 2002.

[13] A. Lasota and Z. Opial, "An application of the Kakutani-Ky-Fan theorem in the theory of ordinary differential equations," Bulletin de l'Académie Polonaise des Sciences. Série des Sciences Mathématiques, Astronomiques et Physiques, vol. 13, pp. 781-786, 1965.

[14] R. F. Curtain and A. J. Pritchard, Functional Analysis in Modern Applied Mathematics, Academic Press, London, UK, 1977. 


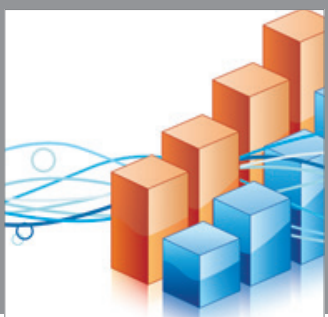

Advances in

Operations Research

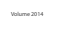

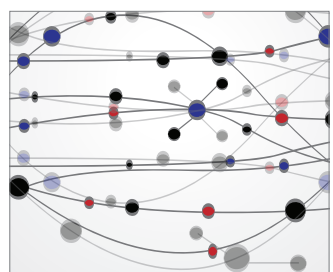

\section{The Scientific} World Journal
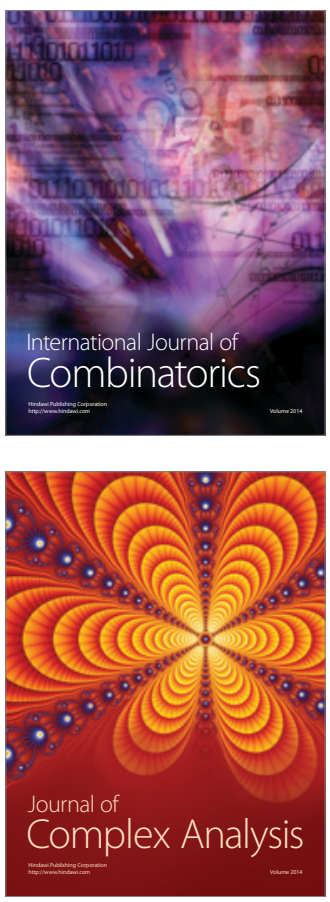

International Journal of

Mathematics and

Mathematical

Sciences
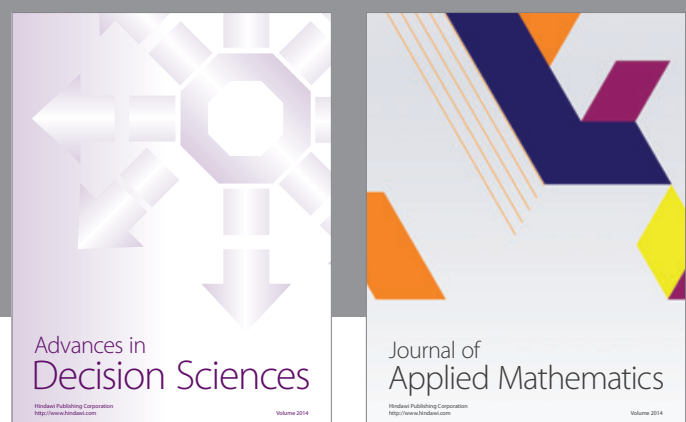

Journal of

Applied Mathematics
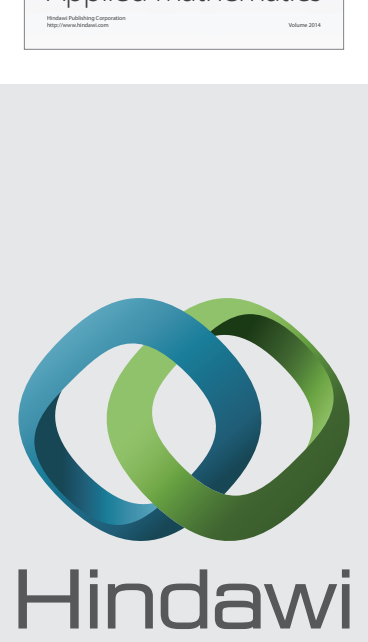

Submit your manuscripts at http://www.hindawi.com
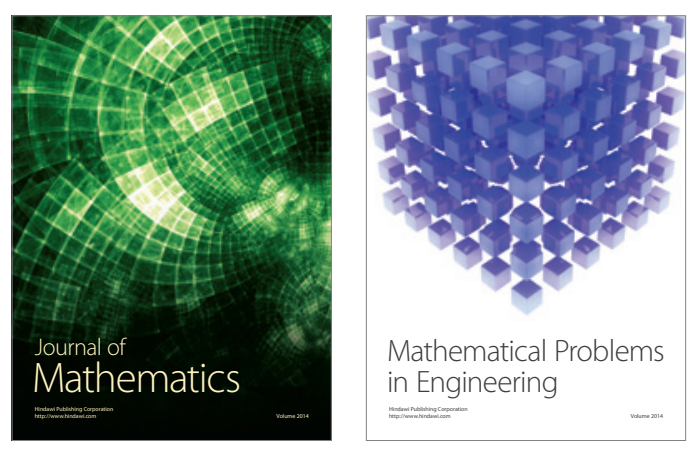

Mathematical Problems in Engineering
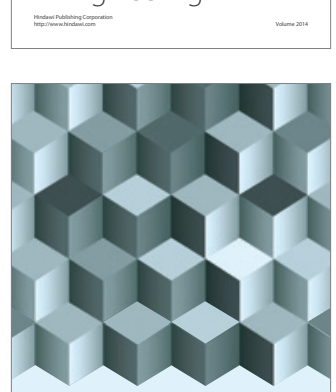

Journal of

Function Spaces
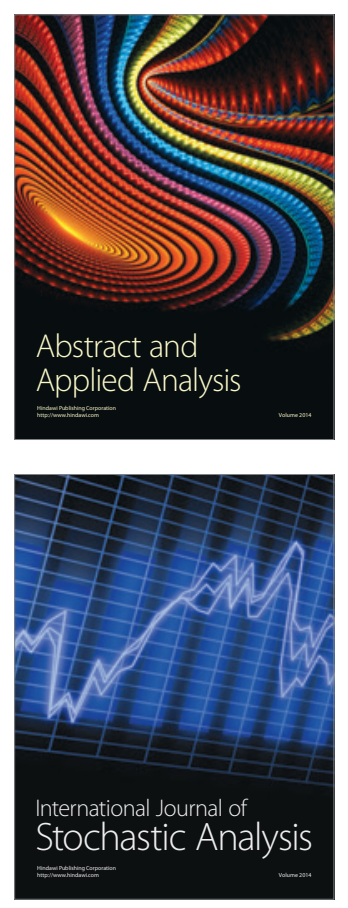

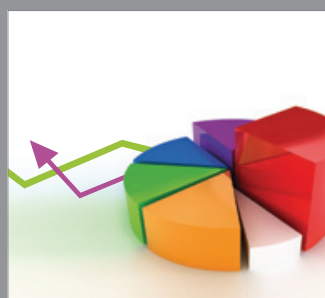

ournal of

Probability and Statistics

Promensencen
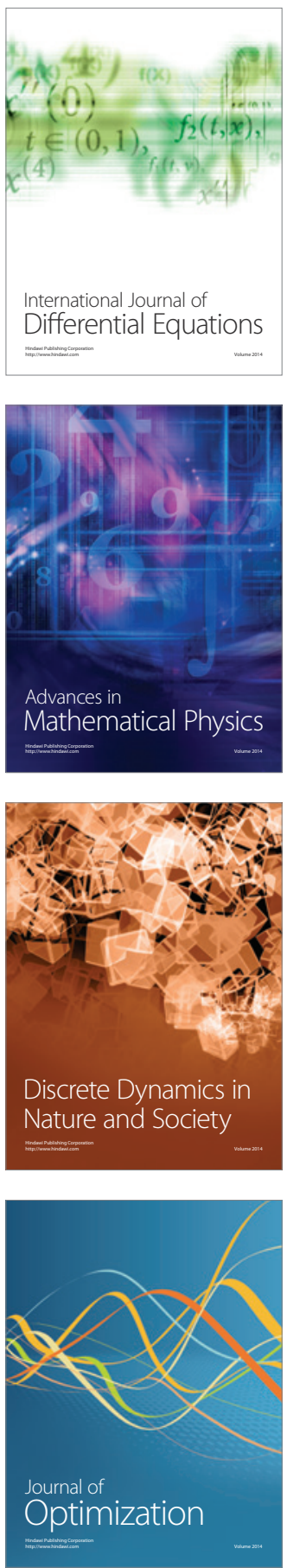